\title{
Gastroprotective Effects of Gloriosa Superba Tubers against HCL/Ethanol Induced Gastric Mucosal Injury in Rats
}

Auhors

\author{
Siddhi Ashokkumar Mehta Falguni ${ }^{1}$, Mrs. Rachana D. Sarawade ${ }^{2}$ \\ Ayyub Shaikh, Vishakha Trivedi, Freny Menezes \\ ${ }^{1}$ Department of Pharmacology, Dr.L.H.Hiranandani College of Pharmacy, Ulhasnagar, Mumbai. \\ ${ }^{2}$ Assistant Professor and HOD Pharmacology, Dr.L.H.Hiranandani College of Pharmacy, \\ Ulhasnagar, Mumbai
}

Abstract
The purpose of this study was to evaluate gastroprotective activity of Gloriosa superba tuber extract
(GSTE) on HCL/Ethanol induced gastric ulcers. Gloriosa superba plant is used for treatment of various
diseases. Disease control group exhibited severe mucosal injury as compared to standard group
(Omeprazole) and test group (GSTE) which showed protection towards gastric mucosal injury. Gastric wall
mucus was significantly replenished by the pre treatment of test group and standard group which was
reduced by HCL/Ethanol. Also antioxidants enzymes (SOD and LPO) were also brought back to normal
level up to certain extent by test drug and Omeprazole.
Keywords: Gastroprotective, Gloriosa superba, SOD, LPO.

\section{Introduction}

Gastric ulcers are one of the most widespread diseases in the world. Gastric ulcers are localized breaches of the gastric mucosa, with tissue destruction at least to the depth of the muscularis mucosa. Gastric ulcer accounts for the highest percentage of affliction among diseases worldwide due to rising levels of stress experienced by humans, alcohol consumption, long term use of anti inflammatory drug intake(Indomethacin, aspirin etc.) that lead to gastric ulcer and nutritional deficiencies. The disruptions between endogenous offensive factors (such as pepsin, hydrochloric acid, refluxed bile, reactive oxygen species) and endogenous defensive factors (such as bicarbonate mucus barrier, mucosal blood flow, prostaglandins, cell proliferation and enzymatic and non enzymatic antioxidant) are important physio-pathological characteristics of gastric ulcers ${ }^{1}$.

Ethanol is widely used to induce experimental gastric ulcer in animals. For the purpose of lesion formation, administration of ethanol was utilized since it rapidly penetrates into the gastric mucus. By increasing mucosa penetrability and release of vasoactive products, ethanol causes vascular damage and gastric cell necrosis which in turn leads to ulcer formation. It is claimed that oxygen free radical play an important role in pathogenesis of gastric damage caused by ethanol ${ }^{2}$.

Most commonly used drugs such as $\mathrm{H}_{2}$ blockers (ranitidine, famotidine), $\mathrm{M}_{1}$ blockers (pirenzepine, telenzepine), proton pump inhibitors (Omeprazole, pentoprazole etc.), decrease the secretion of acids 
while, drugs like sucralfate promote mucosal defences $^{3}$. Although the introduction of the classic anti-ulcer therapy but still there is no complete cure for this disease. It has been shown that long term use of these drugs may be associates with ineffectiveness of different drug regimens and even resistance to drugs are emerging. Hence, efforts are made to introduce suitable treatment from natural products source.

Gloriosa superba is perennial creeper, herbaceous, stout, climbing herb with wavy edged yellow and red flower belonging to family liliacea. Many activities have been reported such as Anti inflammatory, antioxidant, analgesics, antihelmentic, hepatoprotection, anti implantation and anti anxiety etc.

The plant is well documented traditionally in Ayurvedic system of medicine and is used in inflammations, gout, rheumatoid arthritis, and gonorrhoea and relieving fever. Extracts of the tuber are reported to cure ulcer, leprosy, bleeding piles, skin diseases and also have anti-dote property for snake bite. It is classified in Ayurvedic system as Garbhapatani (abotifacient) and used for promoting labour pains. The leaf infusion is extensively used to overcome jaundice, parasitic helminthes infections and killing lice in hair ${ }^{4}$.

\section{Materials And Methods}

\subsection{Plant material}

Tubers of Gloriosa superba was collected from Bharat trading centre, Mumbai. Authentification of these tubers was done from Khalsa college of Arts, Commerce and Science, Mumbai. (Specimen number sm301013).

\subsection{Extraction of Gloriosa superb}

The dried tubers were grinded in mixer to get course. This course powder was used for methanolic extraction. The plant extract was prepared by soxhlet apparatus. 100 gm of powder was repeated extracted with $250 \mathrm{ml}$ methanol as a solvent in a $500 \mathrm{ml}$ R.B.F. The extract was filtered through Whatman filter paper. The filtrate was collected and concentrated by using rotary evaporator under controlled condition of temperature and pressure. The extract was concentrated to dryness to yield crude residue. The concentrated extract was stored in small vials for further use $\mathrm{e}^{5}$.

\subsection{Phytochemical Screening}

Identification of chemical constituents was carried out on the plant extract in order to determine the presence of various phytochemical constituents using specific reagent ${ }^{6}$.

\subsection{Animals}

A total of 24 either sex, Wistar rats, weighing 180-200 gm have been used for experiment. The animals were procured from Bharat serum Ltd, Thane. These animals were acclimatized in animal house of Dr.L.H.Hiranandani college of pharmacy, Ulhasnagar (Registration No879/ac/05/CPCSEA) under standard husbandry condition i.e. room temperature of $24 \pm 10 \mathrm{C}$; relative humidity $45-55 \%$ and 12:12 light dark cycle. The experiments were conducted according to the ethical norms approved by the Institutional animal Ethical committee (IAEC).

\subsection{Acute toxicity studies of Gloriosa superb}

In order to determine the acute toxicity of Gloriosa superba, the animals were divided into two groups, of six rats each. Animals were provided with single dose of $2000 \mathrm{mg} / \mathrm{kg}$ of test drug and control group was provided with vehicle i.e. saline solution. Animals were observed individually after dosing at least once during the first $30 \mathrm{~min}$, periodically during the $24 \mathrm{hr}$, with special attention given during first $4 \mathrm{hr}$ and daily thereafter for a total of 14 days. The parameters observed were diarrhoea, vomiting, salivation, urination, tremor, lethargy, gait, locomotion, adverse behaviour, hypersensitivity.

\subsection{Ethanol induced gastric injury}

In this experiment, effects of Gloriosa superba tuber extract and Omeprazole on HCL/Ethanol induced gastric injury was determined. Animals were divided into four groups of six animals each. Animals were fasted for $24 \mathrm{hr}$ with access to drinking water up till $2 \mathrm{hr}$ before experiment. Animals of Normal group were administered with 
saline, standard group with Omeprazole $(20 \mathrm{mg} / \mathrm{kg}$ ) and test group with test drug (GSTE$110 \mathrm{mg} / \mathrm{kg}$ ). After $1 \mathrm{hr}$ of pre treatment, animals of disease group, standard group and test group were administered with acidified ethanol (150nMHCL/ ethanol) in a ratio of 40:60 v/v. After 60 mins rats were sacrificed and their stomach was removed for further evaluation ${ }^{8}$.

\subsection{Measurement of Acid content of gastric juice}

An equal volume of gastric juice was diluted with equal amount of distilled water and $\mathrm{pH}$ of the solution was measured using $\mathrm{pH}^{\text {meter }}{ }^{9}$.

\subsection{Gastric wall mucus determination}

The glandular segments of the stomach was removed and weighed. Each segment was transferred immediately to $10 \mathrm{ml}$ of $0.1 \%(\mathrm{w} / \mathrm{v})$ Alcian blue solutions (in $0.16 \mathrm{M}$ sucrose solution buffered with $0.05 \mathrm{ml}$ of $0.4 \%$ (w/v) sodium acetate at $\mathrm{pH} 5$ ). Tissues were stained for $2 \mathrm{hr}$ in Alcian blue, excess dye was removed by two successive rinses with $10 \mathrm{ml}$ of $0.25 \mathrm{M}$ sucrose, first for $15 \mathrm{~min}$ and then for $45 \mathrm{mins}$. Dye complexed with gastric wall mucus was extracted with $10 \mathrm{ml}$ of $0.5 \mathrm{M}$ magnesium chloride which was intermittently shaken for $12 \mathrm{~min}$ at $30 \mathrm{~min}$ intervals for $2 \mathrm{hr}$. Four $\mathrm{ml}$ of blue extract was then vigorously shaken with an equal volume of diethyl ether, the resulting emulsion was centrifuged at $1200 \mathrm{~g}$ for $10 \mathrm{~min}$ and the absorbance of aqueous layer recorded at $580 \mathrm{~nm}$. The results are expressed as absorbance per gram (A/g of tissue ${ }^{10}$.

\subsection{Gross gastric lesions evaluation}

Ulcers of gastric mucosa appeared as elongated bands of black hemorrhagic lesions parallel to the long axis of the stomach. Each gastric mucosa was thus examined for damage. Ulcer areas of gastric mucosa were calculated according to the method of Kauffman and Grossman (Kauffman and Grossman., 1978) with slight modification. The length $(\mathrm{mm})$ and width $(\mathrm{mm})$ of the ulcer area on the gastric mucosa were measured by a planimeter $\left(10 \times 10 \mathrm{~mm}^{2}=\right.$ ulcer area $)$ under dissecting microscope (x1.8). The area of each ulcer lesion was measured by counting the number of small squares, $2 \times 2 \mathrm{~mm}$, covering the length and width of each ulcer band. The sum of areas of all lesions for each stomach was applied in the calculation of the ulcer area (UA) where the sum of small squares 4 x $1.8=\mathrm{UAmm}^{2}$. The inhibition percentage (I \%) was calculated by the formula : $(\mathrm{I} \%)=[(\mathrm{UA}$ control- UA treated $) / \mathrm{UA}$ control $] \mathrm{x}$ $100^{11}$.

\subsection{Anti oxidant activity of stomach tissue 2.10.1. Determination of Superoxide dismutase (SOD) activity}

SOD activity was measured according to Sun et al. The activity of the enzyme was evaluated by measuring its capacity to inhibit the phytochemical reduction of nitro blue tetrazolium (NBT). In this assay, the photochemical reduction of riboflavin generates $\mathrm{o}^{2-}$ that reduces the NBT to produce Formazan salt, which absorbs at a wavelength of $650 \mathrm{~nm}$. In the presence of SOD, the reduction of the NBT is inhibited because the enzyme converts the superoxide radical to peroxide. Homogenates $(10 \%$ of tissue in phosphate buffer) were centrifuged (10 minutes, $\left.3,600 \mathrm{rpm}, 4^{\circ} \mathrm{C}\right)$. The resulting supernatant was assayed. In the dark chamber, $1 \mathrm{ml}$ of the reactant (50mM phosphate buffer, 100nM EDTA, and $1.3 \mathrm{nM}$ methionine, $\mathrm{pH} 7.8$ ) was mixed with $30 \mathrm{ul}$ of the sample, $150 \mathrm{ul}$ of $75 \mathrm{uM} \mathrm{NBT}$, and $300 \mathrm{ul}$ of $2 \mathrm{uM}$ riboflavin. The tube containing the resulting solution was then read using a spectrophotometer at $560 \mathrm{~nm}$. The results are expressed as the quantity of SOD necessary to inhibit the rate of reduction of the NBT by $50 \%$ in $\mathrm{u} / \mathrm{g}$ tissue weight ${ }^{8}$.

\subsubsection{Determination of lipid peroxidation (LPO)}

The level of LPO in gastric tissue homogenate was determined by measuring the release of thiobarbituric acid reactive substance (TBARS) in terms of MDA equivalent using

molar extinction coefficient as described by Okhawa et al. Briefly the reaction mixture consisted of $0.2 \mathrm{ml}$ of homogenate, $0.2 \mathrm{ml}$ of $8 \%$ SDS, $1.5 \mathrm{ml}$ of $20 \%$ acetic acid (adjusted to $\mathrm{pH} 3.5$ with $\mathrm{NaOH}$ ), and $1.5 \mathrm{ml}$ of $0.8 \%$ aqueous solution 
of thiobarbituric acid (TBA). The mixture was made for a final volume of $5 \mathrm{ml}$ with distilled water and heated in a water bath for 60 mins. The reaction mixture was then added to $5 \mathrm{ml}$ mixture of n-butanol and pyridine $(15: 1 \mathrm{v} / \mathrm{v})$. The absorbance of the organic layer was measured at $532 \mathrm{~nm}$. Result was expressed in nm MDA per mg wet tissue (nm mg tissue $\left.{ }^{-1}\right)^{12}$.

\subsection{Histopathological examination}

Specimens of the gastric walls of each rat were fixed in 10\% buffered formalin and processed in a paraffin tissue processing machine. Sections of the stomach were made at a thickness of $5 \mathrm{u}$ and stained with Hematoxylin and eosin for histological evaluation.

\section{Statistical analysis}

All values were reported as mean \pm SEM. Results were significantly analysed using one way ANOVA by Dunnett test $\mathrm{p}<0.05$ was considered to be significant.

\section{Results}

\subsection{Phytochemical screening}

Preliminary phytochemical analysis of the methanolic extract of Gloriosa superba revealed the presence of tannins, flavonoids, steroids, alkaloids, and carbohydrates, glycosides and Mucilages.

\subsection{Acute toxicity studies}

Acute toxicity studies was carried out to evaluate toxicity and to determine the minimum lethal dose of the drug extract. It was found that no mortality and changes in the behaviour were observed up to dose of $550 \mathrm{mg} / \mathrm{kg}$. Therefore $1 / 5$ of the $550 \mathrm{mg} / \mathrm{kg}$ dose $(110 \mathrm{mg} / \mathrm{kg})$ was selected for gastroprotective activity.

\subsection{Acid content of gastric juice}

The acidity of disease control group, test group and standard group decreased significantly compared with that of the control group $(\mathrm{p}<0.05$, Table 1 and Graph 1).

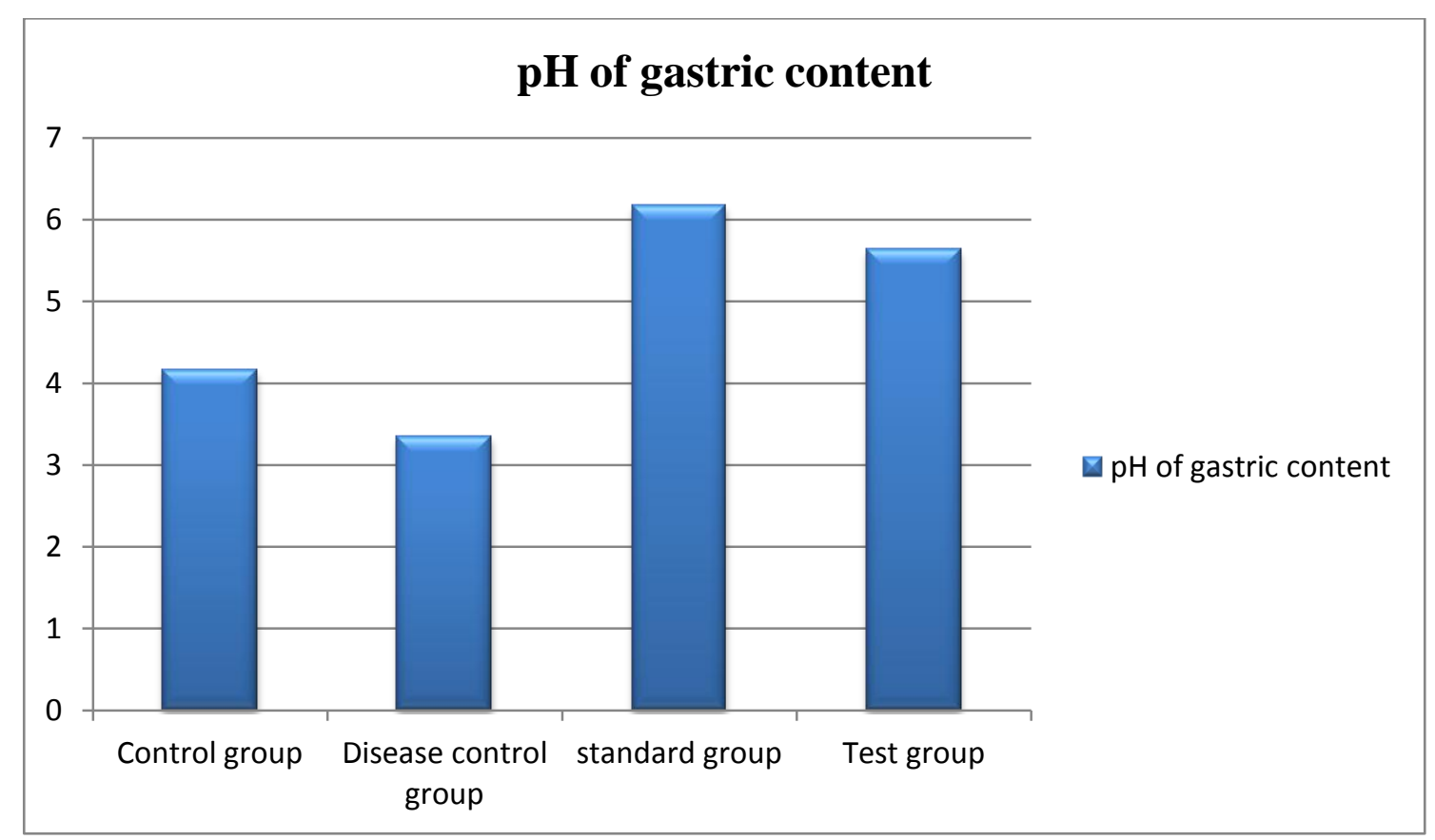

Graph 1: Effect of GSTE on pH of gastric content.

\subsection{Gastric wall mucus determination}

Treatment with HCL/Ethanol caused a decrease in mucus content of the gastric wall. This depleted gastric mucus was significantly replenished after pre-treatment with test drug (GSTE) and standard drug (Omeprazole) (Table 1 and Graph 2). 


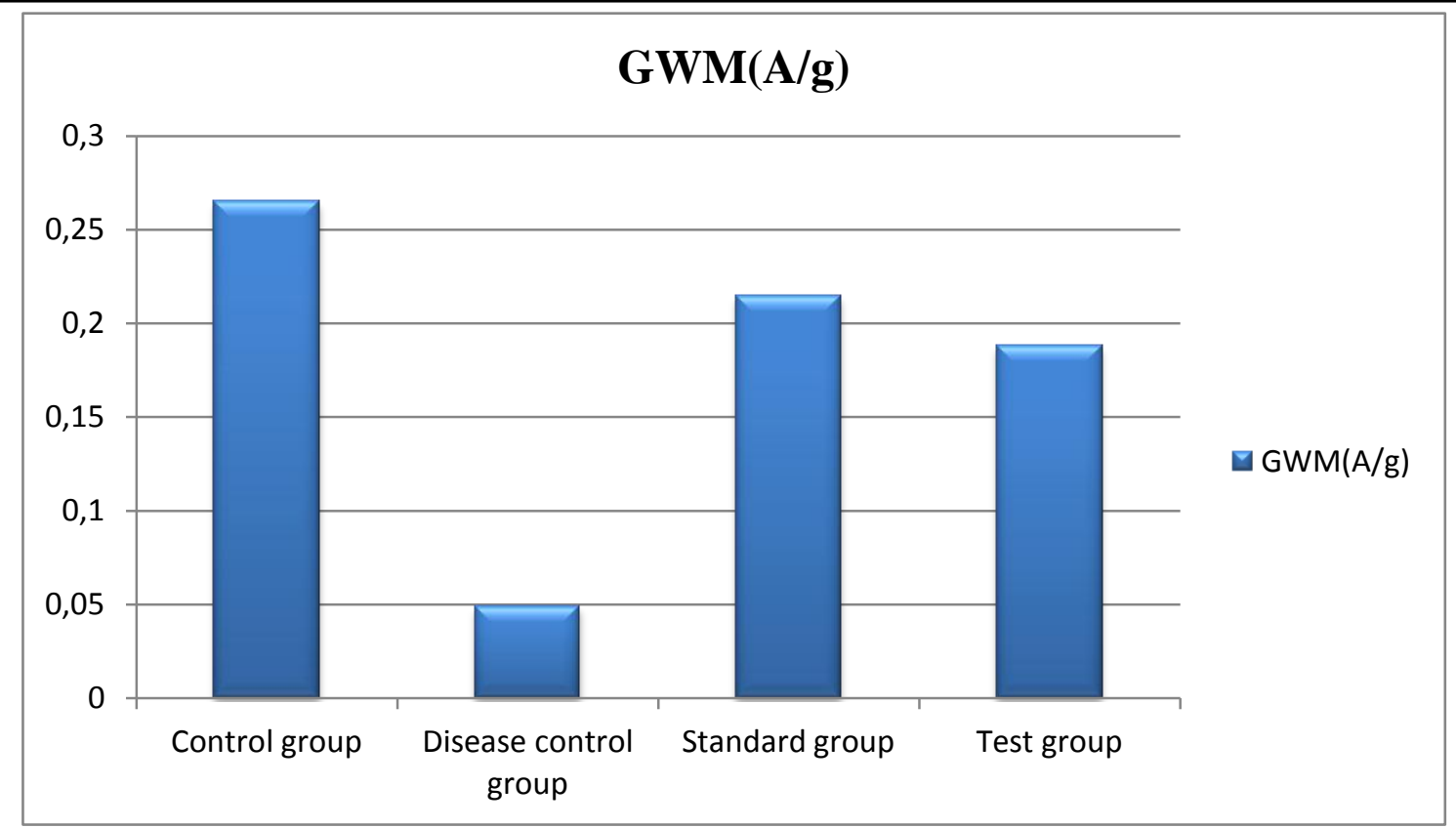

Graph 2: Effect of GSTE on Gastric wall mucus (GWM).

\subsection{Gross gastric acid lesions evaluation}

Acidified ethanol solution produced extensive visible black hemorrhagic lesions of the gastric mucosa. The gastric ulcer formation was significantly reduced with the pre treatment of the test drug (GSTE) and standard drug (Omeprazole) as compared to disease control group. There was significant inhibition of gastric ulcers in rats pretreated with test drug and standard drug was observed (Table 2 and graph 3 ).

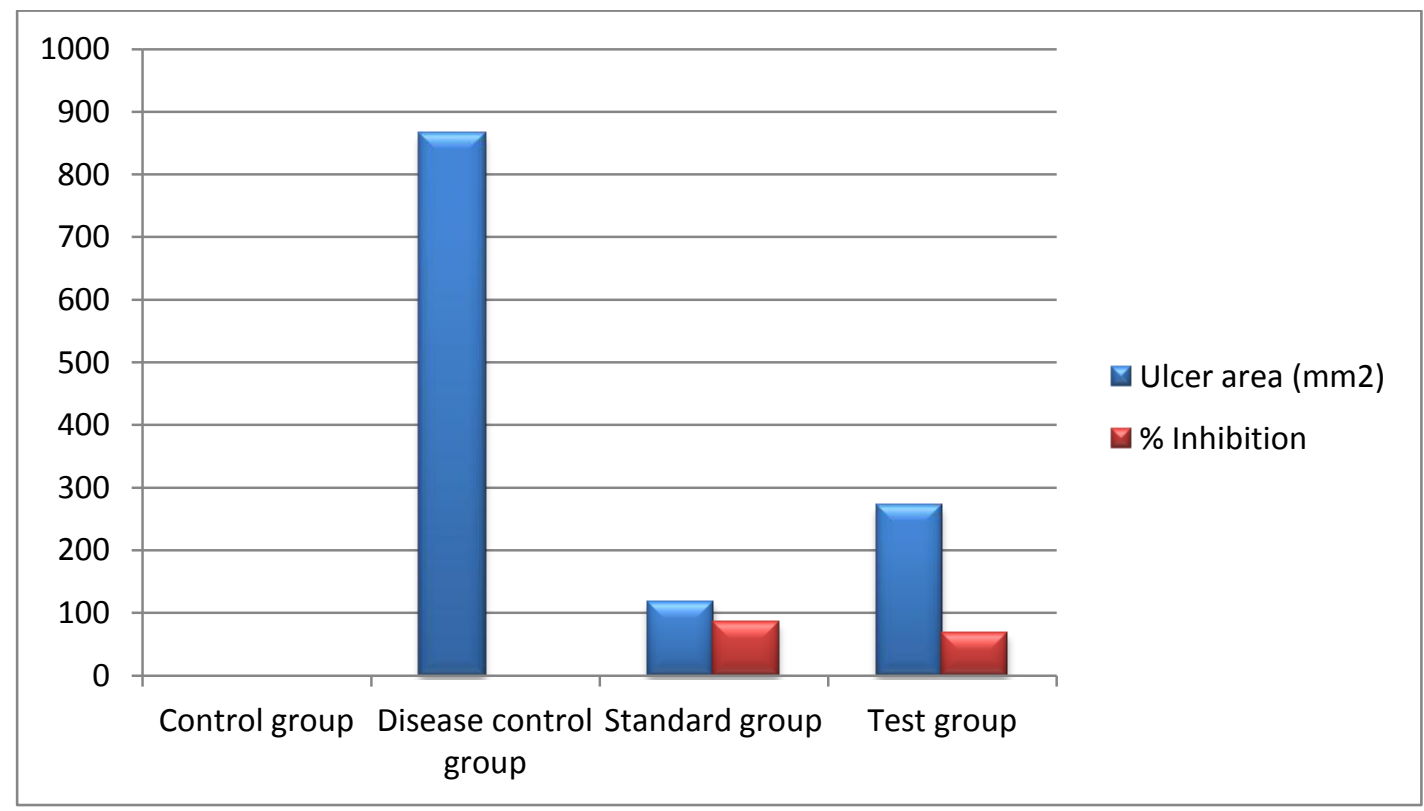

Graph 3: Effect of GSTE on ulcer area and \% Inhibition 


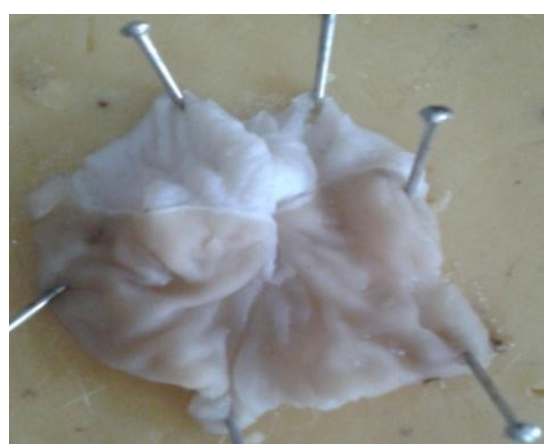

[A] Represents gastric mucosa of control group rat (Saline).

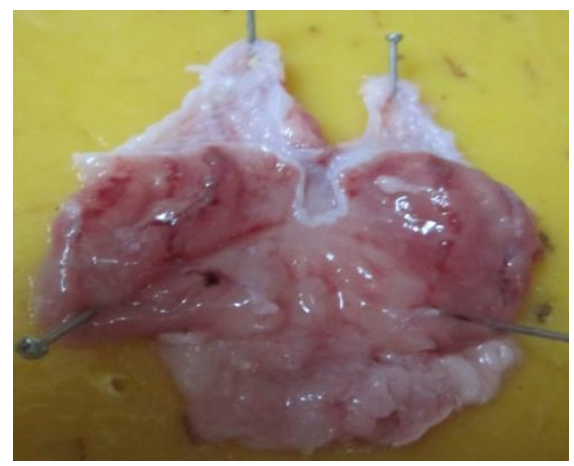

[C] Represents gastric mucosa of Standard group rat (Omeprazole- $20 \mathrm{mg} / \mathrm{kg})$

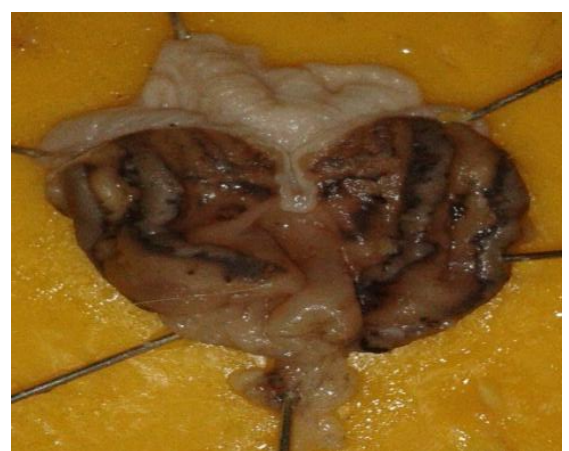

[B] Represents gastric mucosa of disease control group rat (HCL/Ethanol- 3ml/kg).

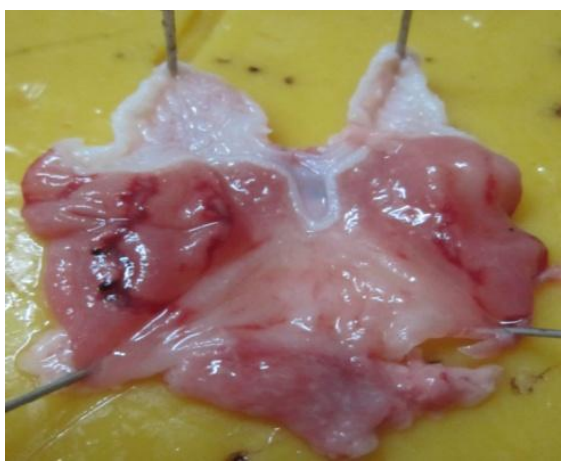

[D] Represents gastric mucosa of test group rat (GSTE-110mg/kg)

Figure 1: Gross appearance of gastric mucosa in rats.

Table 1: Effect of GSTE on gastric $\mathrm{pH}$ and gastric wall mucus.

\begin{tabular}{llll}
\hline Treatment & $\begin{array}{l}\text { Dose } \\
(\mathbf{m g} / \mathbf{k g})\end{array}$ & $\mathbf{p H}$ & $\begin{array}{l}\text { GWM } \\
(\mathbf{A} / \mathbf{g} \text { tissue })\end{array}$ \\
\hline Control & Saline & $4.167 \pm 0.049$ & $0.0265 \pm 0.011$ \\
D.C & $3 \mathrm{ml} / \mathrm{kg}$ & $3.343 \pm$ & $0.049 \pm$ \\
& & $0.048^{* * *}$ & $0.000^{* * *}$ \\
Standard & $20 \mathrm{mg} / \mathrm{kg}$ & $6.170 \pm$ & $0.215 \pm$ \\
& & $0.040^{* * *}$ & $0.003^{* * *}$ \\
Test & $110 \mathrm{mg} / \mathrm{kg}$ & $5.630 \pm$ & $0.188 \pm$ \\
& & $0.020^{* * *}$ & $0.006^{* * *}$ \\
\hline
\end{tabular}

$\mathrm{N}=6$; Each data suggest Mean \pm SEM

One way ANOVA followed by Dennett's test is applied for statistical analysis, $* * *$ significant $\mathrm{p}<0.05$ when disease control, test and standard group compared to control group. 
Table 2: Effect of GSTE on Ulcer area and \% Inhibition.

\begin{tabular}{llll}
\hline Treatment & $\begin{array}{l}\text { Dose } \\
(\mathbf{m g} / \mathbf{k g})\end{array}$ & $\begin{array}{l}\text { Ulcer area } \\
\left.\mathbf{( m m}^{\mathbf{2}}\right)\end{array}$ & $\begin{array}{l}\text { Inhibition } \\
(\mathbf{\%})\end{array}$ \\
\hline Control & Saline & $0 \pm 0$ & 0 \\
\hline D.C. & $3 \mathrm{ml} / \mathrm{kg}$ & $865 \pm 15.06 * * *$ & 0 \\
\hline Standard & $20 \mathrm{mg} / \mathrm{kg}$ & $117.6 \pm 4.886^{* * *}$ & $86.42 \pm 0.563 * * *$ \\
Test & $110 \mathrm{mg} / \mathrm{kg}$ & $271.1 \pm 9.089 * * *$ & $68.69 \pm 1.049 * * *$ \\
\hline
\end{tabular}

$\mathrm{N}=6$; Each data suggest Mean \pm SEM

One way ANOVA followed by Dennett's test is applied for statistical analysis,

$* * *$ Significant $\mathrm{p}<0.05$ when test group and standard group compared to disease control group.

\subsection{Comparison of antioxidant activity in} stomach tissue homogenate

Antioxidant parameters play an important role in ulceration process. Administration of HCL/Ethanol significantly decreases SOD levels in gastric tissues homogenates in decrease control group as compared with control group. This was significantly increased with the rats pre-treated with test drug (GSTE) and standard drug (Omeprazole). In contrast, LPO level was significantly increased in disease control group as compared to control group. With the administration of test drug (GSTE) and standard drug (Omeprazole) there was significant decrease in LPO level as compared to disease control.

Table 3: Effect of GSTE on antioxidant parameters (SOD and LPO).

\begin{tabular}{llll}
\hline Treatment & $\begin{array}{l}\text { Dose } \\
(\mathbf{m g} / \mathbf{k g})\end{array}$ & $\begin{array}{l}\text { SOD } \\
\text { (u/g tissue) }\end{array}$ & $\begin{array}{l}\text { LPO } \\
(\mathbf{n m} / \mathbf{m g} \text { tissue) }\end{array}$ \\
\hline Control & Saline & $2.831 \pm 0.015^{* * *}$ & $14.06 \pm 0.1864 * * *$ \\
\hline D.C. & $3 \mathrm{ml} / \mathrm{kg}$ & $1.745 \pm 0.016$ & $27.78 \pm 0.0366$ \\
Standard & $20 \mathrm{mg} / \mathrm{kg}$ & $2.648 \pm 0.011 * * *$ & $18.29 \pm 0.1670 * * *$ \\
Test & $110 \mathrm{mg} / \mathrm{kg}$ & $2.153 \pm 0.004 * * *$ & $20.13 \pm 0.0797 * * *$ \\
\hline
\end{tabular}

$\mathrm{N}=6$; Each data suggest Mean \pm SEM

One way ANOVA followed by Dennett's test is applied for statistical analysis, ***significant at $\mathrm{p}<0.05$ When test group and Standard group compared to disease control group

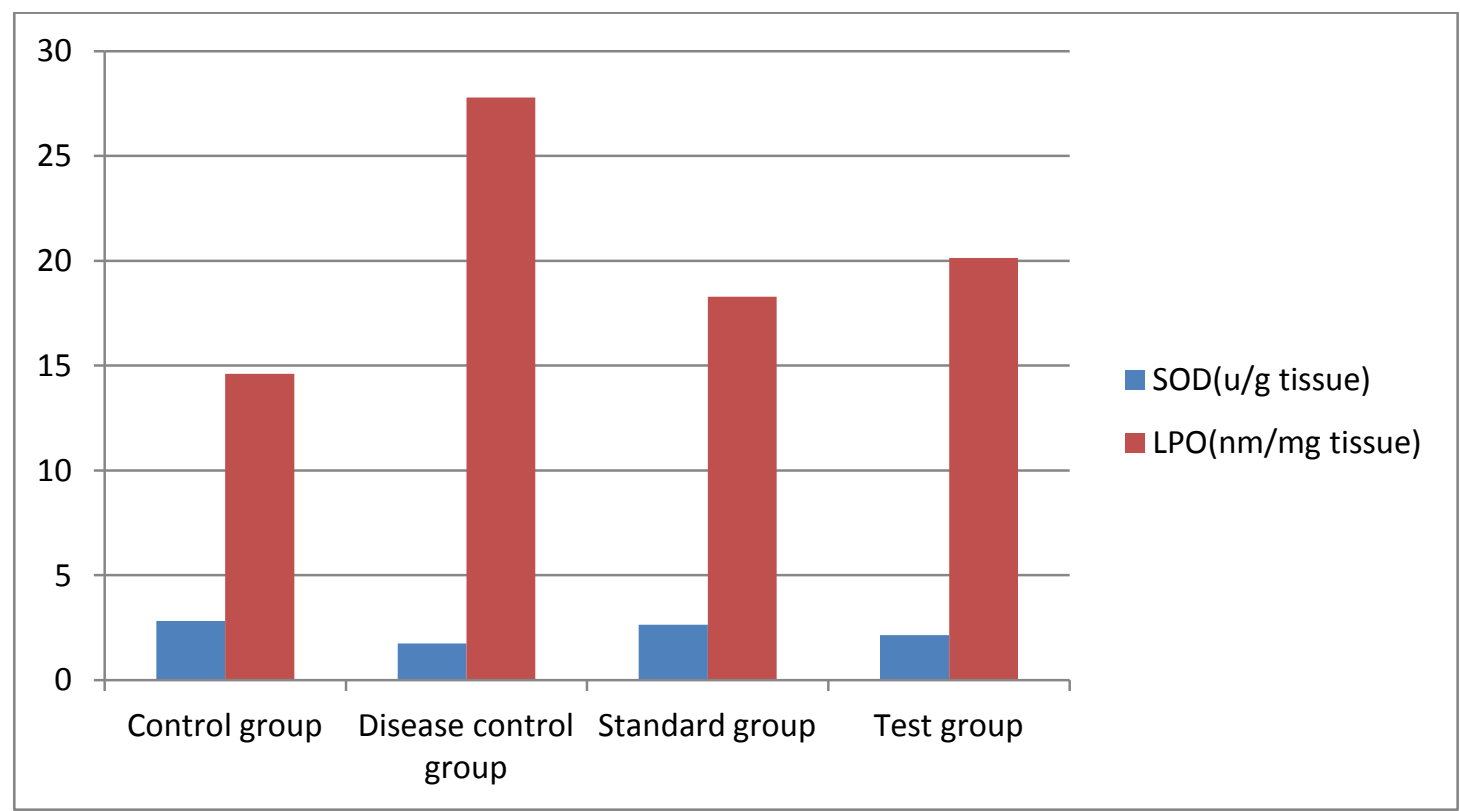

Graph 4: Effect of GSTE on antioxidant parameters (SOD and LPO). 


\subsection{Histopathological studies}

Microscopic examinations of rats given saline did not reveal any lesions of pathological significance. Animals treated with HCL/Ethanol shows very severe destruction of surface epithelium with necrotic lesions extending into deeper part of mucosa (+++) along with moderate submucosal edema $(++)$ and mild to moderate $(++)$ infiltration of leucocytes. Omeprazole treated animals

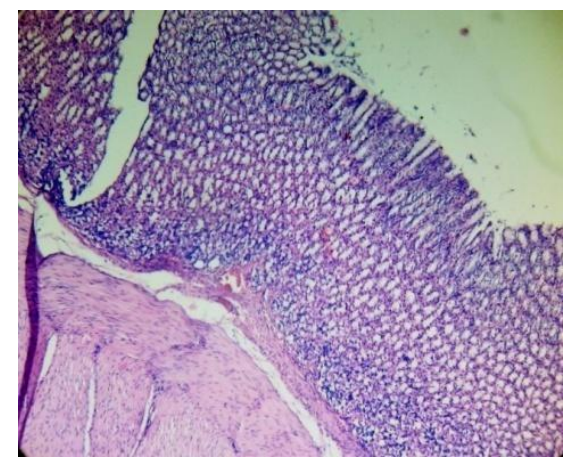

Normal group (Saline)

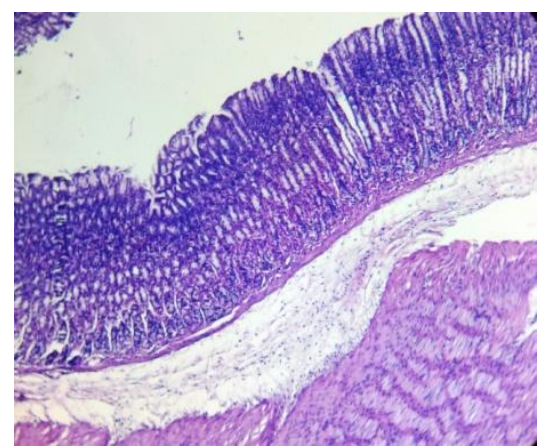

Standard group

(Omeprazole- 20mg/kg) revealed that there was a mild destruction of surface epithelium (+) along with moderate submucosal edema $(++)$. Animals pre treated with test drug (GSTE) shows there was mild destruction of surface epithelium $(+)$ along with mild submucosal edema $(+)$ and mild $(+)$ infiltration of leucocytes.

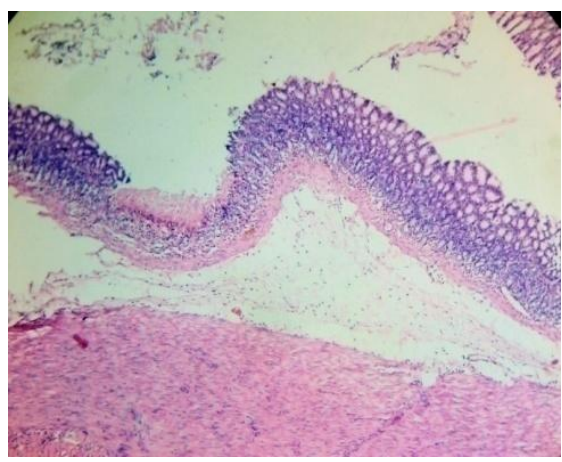

Disease control group (HCL/Ethanol-3ml/kg)

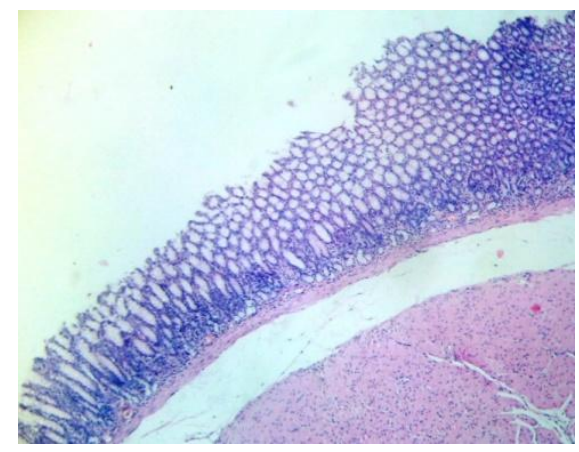

Test group

(GSTE-110mg/kg)

Figure 2: Histopathological images of Ethanol induced model

\section{Discussion}

Gastric ulcer are the most common gastrointestinal disease which are chronic and recurrent. It is believed that they occur because of the disequilibrium between potentially injurious and protective factors of the gastric mucosa.Gloriosa superba tuber showed the presence of Flavonoids, tannins, glycosides, steroids secs, Alkaloid, carbohydrates and mucilages. No toxic reactions were observed from acute toxicity study, thereby suggesting non toxic nature of plant(GSTE) at the dose of $550 \mathrm{mg} / \mathrm{kg}$. Ethanol causes necrotic lesions in many ways. It can reach mucosa by distruption of the mucus- 
bicarbonate barrier and causes cell rupture in the wall of blood vessels.the pathogenesis of ethanol induced gastric mucosal damage occurs directly and indirectly through various mediators such as lipoxygenase, cytokines and oxygen-derived free radicals. Mucus secrtion is regarded as a crucial defensive factor in the protection of the gstric mucosa from gastric lesions.

The experimental results of the study showed that Gloriosa superba extract has an effective gastroprotective activity against ethanol induced gastric mucosal injury. The plant extract decreased acidity and increases the gastric wall mucus. Pre treatment with GSTE and omeprazole could partly reduce the ulcer area and prevent gastric ulceration. Gloriosa superba extracts have been shown to contain antioxidants and its likely that gastroprotective activity exerted by this plant could be attributed to its antioxidant property. In the current study activity of SOD was reduced and level of LPO was increased after administration of HCL/ethanol in disease control group. And this parameters were brought back to its level upto certain extend with the pre treatment of $\operatorname{GSTE}(\mathrm{p}<0.05)$.

\section{Conclusion}

It can be concluded that HCL/Ethanol induced gastric mucosa injury by various mechanisms. With the pre treatment of GSTE shows that gastric ulcers were significantly reduced and reducing effect against oxidative damage. Also gastric wall mucus was also replenished. Therefore GSTE can be used as gastroprotective agent. Further experiments and clinical studies are needed for confirmation.

\section{Acknowledgement}

With the guidance and support, I received, I would to thank from the bottom of my heart, my guide Mrs. Rachana D. Sarawade. I would like to thank my principle, Dr. Parag Gide and also my college Dr.L.H.Hiranandani College of pharmacy for providing suitable environment for research work and facilities. I would like to thank my teaching and non teaching staff. I am glad to thank almighty god, my parents, colleagues and everybody who are indirectly connected to my research work.

\section{References}

1. Walaa Najm Abood, Mahmood A. Abdulla and Salmah Ismail; Involvement of Inflammatory mediators in gastroprotective action of Phaleria macrocarpa against Ethanol-induced gastric ulcers; World applied science journal 30; 344-350,2014.

2. Manal Mohamed Elhassan Taha, Muhammad Saleh Salga, Hapipah Mohd Ali, Mahmood Ameen Abdulla, Siddiq Ibrahim Abdelwahab, A.Hamid A. Hadi; Gastroprotective activities of Turnera diffusa wild.ex schult; revised : role of arbutin; journal of Ethanopharmaology; 141(2012) 273-281.

3. M.Dorababu, M.C.Joshi, Bhawani G., M.Mohankumar, Aditi Chaturvedi and R.K.Goel; Effect of Aqueous extract of neem (Azadiracta Indica) leaves on offensive and defensive gastric mucosal factors in rats; Indian J Physiol Pharmacol 2006; 50(3); 241-249.

4. KP.Latha, H.Kirana and HN.Girish; AntiImplantation activity of the hydro alcoholic tuber extract of Gloriosa superba Linn in female Albino rats; IJAPBC-vol.2 (3); jul-sep, 2013.

5. Saradha devi Muthukrishnan, Annapooorani Subramaniyam; International journal of pharmaceutical research development (IJPRD); 2013; vol 5(06) Aug-2013(102-108).

6. CK Kokate, Practical Pharmacognosy; $4^{\text {th }}$ edition; Vallabh Prakashan; New Delhi.

7. GE Trease, WC Evans; Pharmacognosy, $15^{\text {th }}$ edition; WB Saunders Publishers.

8. Ahmed S. AlRashidi, Suzy M.Salama, Salim S. Alkiyumi, Mahmood A Abdulla, A. Hamid A. Hadi, Siddig I.Abdelwahab, 
Manal M Taha, Jamal Hussiani, and Nur Asykin; Mechanism of gastroprotective effect of ethanolic leaf extract of Jasminium sambac against $\mathrm{Hcl} /$ Ethanol induced gastric mucosal imjury in rats; Hindawi Publishing Corporation, Volume 2012, Article ID 786426.

9. N.L. Dashputre, N.S. Naikwade; Evaluation of Anti-ulcer activity of methanolic extract of Abutilon indicum Linn leaves in experimental rats; International journal of pharmaceutical sciences and drug research 2011; 3(2); 97100.

10. J.Mojzis, R.Hegedusova, L.Mirossay; Role of mucus in ischemia/Reperfusion-induced gastric mucosal injury in rats; Physiol.Res.49:441-446, 2000.

11. Mahmood Ameen Abdulla, Khaled AbdlAziz Ahmed, Fouad Hussain Al-Bayaty and Yaghma Masood; Gastroprotective effect of Phyllanthus niruri leaf extract against ethanol- induced gastric mucosal injury in rats; African journal of pharmacy and pharmacology; vol 4(5); pp.226-230; may 2010.

12. K.T. Mani, Senthnil Kumar 1, Zothan Puia1, Samir K. Samanta1, Rajiv Barik 1, Arnab Dutta 1, Bapi Gorain 1, Dilip K. Roy1, Dipan Adhikari 1, Sanmoy Karmakar1, Tuhinadri Sen; The gastroprotective role of Acanthus ilicifolius- A study to unravel the underlying mechanism of Anti-ulcer Activity; sci Pharm. 2012; 80: 701-717. 